\title{
A Review of Microfabricated Electrochemical Biosensors for DNA Detection
}

\author{
Ewen O. Blair* and Damion K. Corrigan
}

Department of Biomedical Engineering,

University of Strathclyde, Glasgow, G4 ONS, UK

*Corresponding author: ewen.blair@strath.ac.uk

\begin{abstract}
This review article presents an overview of recent work on electrochemical biosensors developed using microfabrication processes, particularly sensors used to achieve sensitive and specific detection of DNA sequences. Such devices are important as they lend themselves to miniaturisation, reproducible mass-manufacture, and integration with other previously existing technologies and production methods. The review describes the current state of these biosensors, novel methods used to produce them or enhance their sensing properties, and pathways to deployment of a complete point-ofcare biosensing system in a clinical setting.
\end{abstract} Keywords: biosensor, microfabrication, electrode, DNA sensor, thin films

\section{Introduction}

Biosensor is a commonly used and broad term, which describes almost any sensor with a biological component. These tend to take the form of a layer of complex molecules attached to a sensor, where target binding or a change in the molecules which comprise the sensing layer causes a physical change which can be measured by the underlying device. This ensures bio-recognition or signal specificity and enables the physical sensor to detect the presence of biological targets that would typically be unavailable to it, such as specific proteins, DNA/RNA sequences, and bacteria species. Numerous different biological detection methods have arisen, with popular ones including: surface 
plasmon response (SPR), Raman and surface-enhanced Raman spectroscopy (SERS), vibration of mechanical cantilevers, and electrochemical measurements (Arlett et al., 2011; Hansen and Thundat, 2005; Homola, 2003; Ngo et al., 2015; Š́pová and Homola, 2013; Wang, 1999; Wolfbeis, 2008). Electrochemical methods have received widespread attention due to the relative simplicity and cost-effectiveness of the required set up in addition to their ease of miniaturisation (Drummond et al., 2003; Ferapontova, 2017; Grieshaber et al., 2008).

DNA biosensors allow for the detection and quantification of specific DNA sequences. Despite these already proving a very useful analytical tool, it is the clinical setting where these devices have the potential for the highest impact. The ability to rapidly determine the presence of a certain DNA sequence in a clinical sample means rapid diagnoses of almost any disease from non-communicable (e.g. cancer) to infectious (e.g. HIV, malaria and sepsis), as well as the presence of poisons like pesticides and is an important means for determining the presence of antibiotic resistance (Liu et al., 2019; Kumar, 2019; Diculescu, 2005; Bartosik and Jirakova, 2019). Combined with the benefits of microfabrication and lab-on-a-chip approaches, it is not surprising that electrochemical DNA sensors for biomedical applications are a popular area of research.

The operation of an electrochemical DNA sensor generally starts by forming a selfassembled monolayer (SAM) of single stranded (ss)DNA on the surface of an electrode. This DNA has been designed as a genetic recognition sequence which will only bind to a specific target strand of interest. The DNA modified electrode is incubated in a sample solution and any target DNA in the solution is hybridised with the probe strand to give double stranded (ds)DNA on the electrode surface. In a complex mixture, such as a clinical sample where background DNA is present, any of the complementary target sequences which are present will bind to the probe DNA immobilised on the electrode. Measurements of an electrochemical parameter which is dependent on the state of the monolayer are performed before and after this hybridisation step. These can include the changes in double layer capacitance, charge transfer through the DNA film via a solution based redox mediator, or electron transfer currents from a redox label bound to the probe sequence or target DNA. An example of a commonly used detection method is presented in figure 1 ( $\mathrm{Li}$ et al., 2017; Grieshaber et al., 2008; Wang, 2006). 
A negatively charged redox molecule is measured using electrochemical impedance spectroscopy (EIS) at an electrode surface, shown in figure 1 (a). A ssDNA probe layer reaction, as in figure 1 (b). After hybridization with the target in figure 1 (c), the amount of DNA in the film increases, further raising the charge transfer resistance, shown in figure $1(\mathrm{~d})$.

(a)
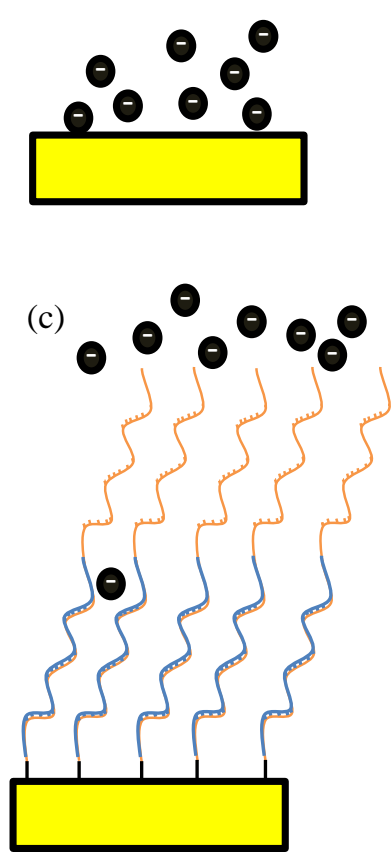

(b)

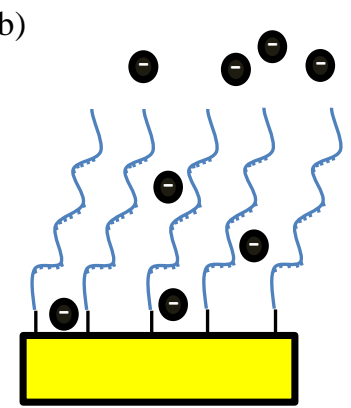

(d)

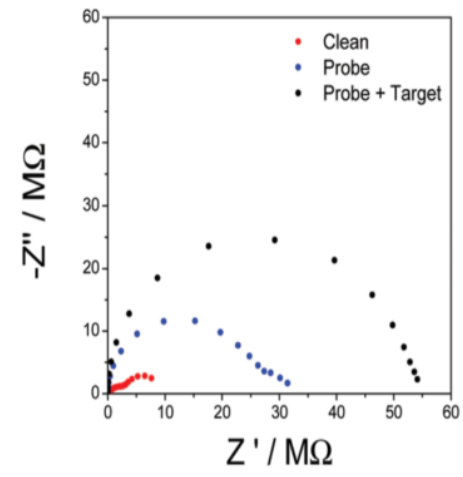

Figure 1: An example of an approach to DNA detection using electrochemical impedance spectroscopy and measurement of a negatively charged redox couple (a) on a bare electrode surface, (b) after functionalisation with probe DNA (blue), (c) after hybridisation with target DNA (green) and (d) an example of such measurements made with electrochemical impedance spectroscopy, showing the impedance increasing after each step. Adapted from (Li et al., 2017) with permission from The Royal Society of Chemistry. 

such as improving sensor specificity and limits of detection. However, even once these goals are satisfactorily achieved the further problem of manufacturing the sensor becomes apparent. This is especially pertinent as many biosensing strategies have involved modification of electrodes with materials such as nanoparticles and graphene, or even bespoke polymers. The difficulty with these devices is their capacity for production, not only on a large scale but also with repeatable performance. A solution to this is the use of microfabricated sensors (Wang, 2000). At present, microfabrication processes are quite mature and responsible for the mass manufacture of millions of complex electronic components every year. The benefits of developing a sensor system with such processes in mind not only enables the large-scale production of nominally identical sensors, but the integration of them with a myriad of different technologies (Blair et al., 2015; Marland et al., 2018.). This includes wireless and smartphone technology which is covered in a recent review on wireless chemical and biosensors by Kassal et al. (Kassal et al., 2018). This helps realize the goal of lab-on-a-chip style systems, where the sensor is combined with signal processing and read out electronics on a single platform. Then the chip can be combined with microfluidic packaging for sample processing and delivery (Buchoux et al., 2017; Lafleur et al., 2016). The end result is a complete point-of-care system which can be cheaply manufactured and easily used without specialized training. This review will focus on the current state of biosensors which are compatible with microfabrication processes. The goal of this review is to cover the recent literature in this area and provide readers new to the field with a roadmap for fabrication of their own systems, which best suit the requirements of their application. Other forms of microfabricated DNA sensors exist such as FieldEffect Transistor (FET) based sensors and those based on selective nanopores. These will not be investigated here and an interested reader is pointed to several relevant reviews (Howorka et al., 2001; Mattiasson and Hedström, 2016; Veigas et al., 2015). Table 1 contains a list of other recent reviews that expand areas touched on in this work giving the reader an oversight into the field of biosensors, as well as showing where this review fits into the literature. This review will first look at work involving common thin film materials used to make DNA biosensors, including their benefits and drawbacks. The effects of miniaturization will then be investigated, looking at research 
conducted using microfabricated microelectrodes and nanoelectrodes as well as previous attempts to integrate these onto complimentary metal-oxide-semiconductor (CMOS) chips. Microfluidics and chip packaging are then looked at, followed by 105 investigating the uses of different electrochemical measurement techniques. Finally, a summary of the direction of microfabricated DNA biosensors will be presented. 


\begin{tabular}{|c|c|c|c|}
\hline Title & Year & Description & Ref \\
\hline $\begin{array}{l}\text { Micro- and nano-structure based } \\
\text { oligonucleotide sensors }\end{array}$ & 2015 & $\begin{array}{l}\text { Miniaturized DNA biosensors, } \\
\text { not electrochemical }\end{array}$ & $\begin{array}{l}\text { (Ferrier et al., } \\
\text { 2015) }\end{array}$ \\
\hline $\begin{array}{c}\text { Metal oxide nanoparticles in } \\
\text { electrochemical sensing and biosensing: } \\
\text { a review }\end{array}$ & 2018 & $\begin{array}{l}\text { Reviews the use of } \mathrm{MO}_{\mathrm{x}} \\
\text { nanoparticles to improve } \\
\text { biosensor performance }\end{array}$ & $\begin{array}{l}\text { (George et al., } \\
\text { 2018) }\end{array}$ \\
\hline $\begin{array}{l}\text { Graphene, carbon nanotubes, zinc } \\
\text { oxide and gold as elite nanomaterials for } \\
\text { fabrication of biosensors for healthcare }\end{array}$ & 2015 & $\begin{array}{l}\text { Looks at the impact of } \\
\text { modifying biosensors with certain } \\
\text { nanomaterials }\end{array}$ & $\begin{array}{l}\text { (Kumar et al., } \\
2015)\end{array}$ \\
\hline $\begin{array}{l}\text { Understanding the Factors Affecting } \\
\text { the Analytical Performance of Sandwich- } \\
\text { hybridization Genosensors on Gold } \\
\text { Electrodes }\end{array}$ & 2018 & $\begin{array}{l}\text { Focusses on sandwich-type } \\
\text { assays, where the target of interest } \\
\text { is labelled with an additional } \\
\text { molecule to improve detection. }\end{array}$ & $\begin{array}{l}\text { (Miranda- } \\
\text { Castro et al., } \\
\text { 2018) }\end{array}$ \\
\hline $\begin{array}{l}\text { Recent advances in lab-on-a-chip for } \\
\text { biosensing applications }\end{array}$ & 2016 & $\begin{array}{l}\text { Investigates biosensors which } \\
\text { have integrated fluidic } \\
\text { manipulation }\end{array}$ & $\begin{array}{l}\text { (Lafleur et al., } \\
\text { 2016) }\end{array}$ \\
\hline $\begin{array}{l}\text { Structured thin films as functional } \\
\text { components within biosensors }\end{array}$ & 2005 & $\begin{array}{l}\text { An introduction to the } \\
\text { formation of self-assembled } \\
\text { monolayers, how they are } \\
\text { measured and their applications. }\end{array}$ & $\begin{array}{r}\text { (Davis and } \\
\text { Higson, 2005) }\end{array}$ \\
\hline This review & 2019 & $\begin{array}{l}\text { Reviews biosensors fabricated } \\
\text { on different types of thin film, as } \\
\text { well as the impact of } \\
\text { miniaturization and their } \\
\text { capability for manufacture. }\end{array}$ & - \\
\hline
\end{tabular}

Table 1: A comparison of recent reviews in the area of biosensor development 


\section{Main Text}

\section{Thin Film Electrode Materials}

\subsection{Gold}

The most common material typically used for microfabricated biosensor electrodes is gold. Such thin films are usually sputtered or evaporated between thicknesses of $10-$ $500 \mathrm{~nm}$ (Díaz-Serrano et al., 2011; Hong et al., 2018; Hsu et al., 2016; Soraya et al., 2018). Full microfabrication processes on silicon wafers can be very expensive and many groups instead use glass slides, for example Capaldo et al. used a lift-off process to pattern gold on a microscope slide and then used SU-8 photoresist as an insulator as depicted in figure 2 (Capaldo et al., 2016). They characterized the device using complementary ssDNA and found a limit of detection (LoD) of $1 \mathrm{pM}$. They then went on to detect miRNA in complex serum, against a general DNA background in the nanomolar concentration range.

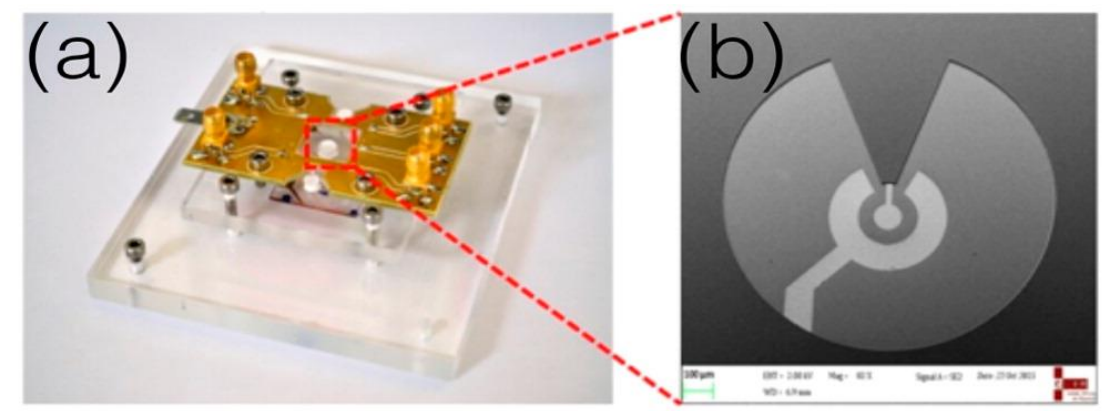

Figure 2: A microfabricated two-electrode sensor used by Capaldo et al. for salmonella detection. (a) The set up that housed the electrodes and (b) a scanning electron microscope (SEM) image of the gold electrodes masked by SU-8 insulator. Adapted with permission from (Capaldo et al., 2016). Copyright (2016) American Chemical Society.

An advantage of this kind of thin film patterning is the straight-forward incorporation of multiple electrodes on a single substrate. It is therefore fairly common for gold electrodes to be accompanied by a counter and reference electrode or sometimes a single, combined counter/pseudo-reference electrode (more common in integrated lab 
on a chip systems, as the development of true thin film reference electrodes still presents a challenge (Shinwari et al., 2010; Suzuki et al., 1998)). Uludag et al. designed multiple gold two-electrode cells on a glass slide using a laser cut stainless steel mask (Uludag et al., 2014). The electrodes were then packaged in a poly(methyl methacrylate) (PMMA) flow cell. They studied the effect of each working electrode having a separate counter and pseudo-reference electrode, compared to a shared one for all the electrodes. What was found was that the shared pseudo reference electrode design gave the most stable result, with no shift in peak potential with scan rate. It is also noteworthy that the larger current density was measured using the smallest electrode designs $(1.5 \mathrm{~mm}$ diameter), demonstrating that the electroanalytical performance of a sensor improves as its physical dimensions are reduced.

Despite the popularity of two-electrode cells, many groups prefer the addition of a reference electrode. The reason for this is exemplified by Ianeselli et al, who investigated the performance and stability between a two-electrode and three-electrode set up when detecting DNA hybridization (Ianeselli et al., 2014). They found that the two electrode system was less stable with the working electrode potential drifting over time. This was explained by electrochemical reactions causing changes at the combined counter/pseudo-reference electrode surface, resulting in an unstable reference potential. The advantage of the reference electrode was also demonstrated García et al., who utilized a patented silver thin film reference electrode and used it in combination with a gold working electrode and a platinum counter electrode to measure synthetic salmonella DNA (García et al., 2012). Their device demonstrated a LoD of 208 nM. The stability of the reference electrode was proven over long term experiments, with the sensor reported to be able to detect salmonella over the course of three months.

As well as stability, the sensitivity of these types of sensor usually requires enhancement of the sensor design and a common strategy for improving sensitivity is nanostructuring the surface of the detection electrode. This makes the sensors more complex to manufacture, especially in a reproducible manner and despite many excellent results presented in literature with these nanostructured surfaces, only a few of these strategies are currently compatible with microfabrication processes. One example is the Şeker group, who used sputtering to deposit a mixed thin film of silver and gold before dealloying the silver in a nitric acid wet etch (Daggumati et al., 2015; 
Matharu et al., 2017). This resulted in a nanoporous thin film electrode, demonstrated in figure 3. Through heating or cyclic voltammetry $(\mathrm{CV})$, they were able to control the nanopore size, arriving at an optimal pore size of 20 - $30 \mathrm{~nm}$ for DNA hybridization detection. Another method was demonstrated by Rho et al. who achieved a nanoporous surface by anodizing, annealing, then re-anodizing again Niobium foil to give nanoporous niobium oxide (Choi et al., 2007; Rho et al., 2008). The textured niobium oxide film was sputter coated with $50 \mathrm{~nm}$ of gold to give a current density three times higher than that of a control bulk gold electrode. Other techniques that have been investigated include laser nanomachining of gold surfaces and spin coating nanospheres for photolithographic production of gold nanoparticle arrays (Purwidyantri et al., 2016; Sylvestre et al., 2004).
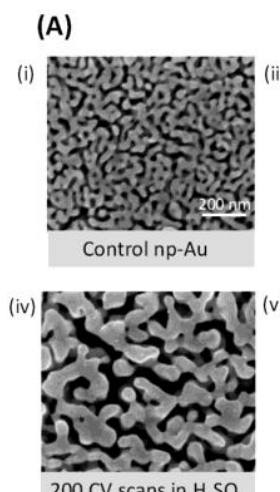

$200 \mathrm{CV}$ scans in $\mathrm{H}_{2} \mathrm{SO}_{4}$
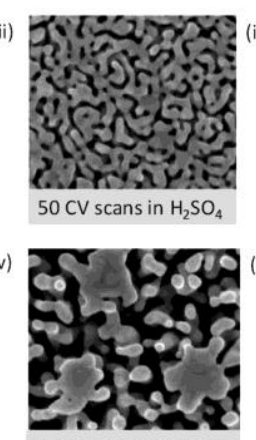
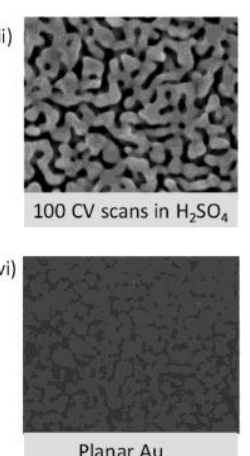

(B)
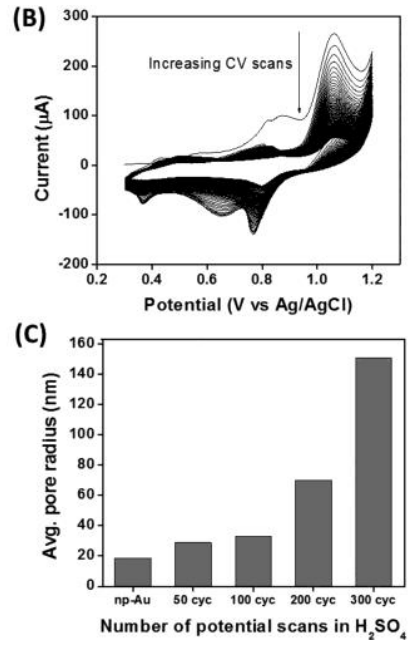

Figure 3: (A) (i)-(vi) SEM images of gold nanopores created by Matharu et al. through dealloying silver from a mixed gold/silver thin film. Cyclic voltammetry has then been performed to controllably increase the pore size, with (B) showing CVs of the gold film over time in $\mathrm{H}_{2} \mathrm{SO}_{4}$ solution and (C) the average pore radius increasing with the number of CV scans. Reprinted with permission from (Matharu et al., 2017). Copyright (2017) American Chemical Society. 
The use of microfluidic cells has also been shown to improve thin film biosensor performance, as well as moving the technology towards point of care applications (Berdat et al., 2007; Koydemir et al., 2014). This improvement in sensing performance was evidenced by Horny et al. who compared a standard $25 \mu \mathrm{m}$ diameter gold wire microelectrode, with a thin film $30 \mu \mathrm{m}$ wide band microelectrode set in a microfluidic channel (Horny et al., 2016). The standard microelectrode was able to detect a microRNA sequence for liver function in the 10-100 $\mathrm{fM}$ range, while the microelectrode positioned in the microfluidic channel showed a LoD of 1-10 aM when liquid was flowing through the microchannel. The authors also compared the performance of the system when the solution in the microchannel was still and found the LoD to be $100 \mathrm{aM}$. Microfluidic cells like the one used above are usually made from polymers such as Polydimethylsiloxane (PDMS) or Parylene-C. These have the advantage of being lithographically patterned as well as showing good biocompatibility. Miniaturized valves have also been integrated into microfluidic systems, enabling more advanced manipulation of samples. An example of a system like this was developed by Ben - Yoav et al., who used flexible membranes to close off microfluidic channels using pressurized air (Ben-Yoav et al., 2015). This was combined with thin film gold electrodes and a theoretical LoD of $1 \mathrm{nM}$ for complementary target DNA was achieved. 
Parylene $-\mathrm{C}$ is a polymer commonly used in the microfabrication industry for insulation and can be deposited conformally, without pinholes. It has advantages over PDMS in that it is not oxygen permeable, although it can be challenging to deposit and pattern in thicknesses greater than single microns. Koydemir et al. used Parylene - C to create a simple on-chip microfluidic system and demonstrated detection of synthetic MRSA target DNA down to $10 \mathrm{pM}$, with a maximum thickness of Parylene $-\mathrm{C}$ of approximately $20 \mu \mathrm{m}$ (Koydemir et al., 2014). PMMA is another alternative to PDMS and was put to use by Liu et al. who fabricated a sophisticated microfluidic system designed for processing blood samples, shown in figure 4 (Liu et al., 2018). The system had in-line filtration, exothermic lysis, hybridization, and washing before the sample was delivered to a detection chip. The chip employed thin film gold electrodes, which had been nanostructured by electrodeposition. Although the LoD was not investigated, the system qualitatively detected the presence of hepatitis C DNA in mock patient blood samples.

Gene amplification is a common method of increasing the concentration of target DNA to detectable levels and has frequently been used to ease the burden of sensitivity

A

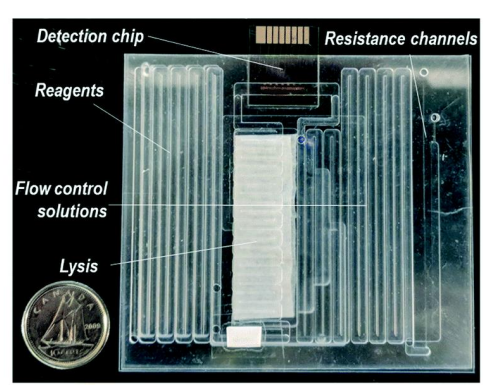

C 1) Sample addition 2) Exothermic reaction 3) Exothermic lysis

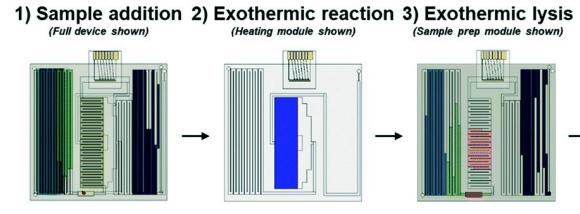

\section{B}

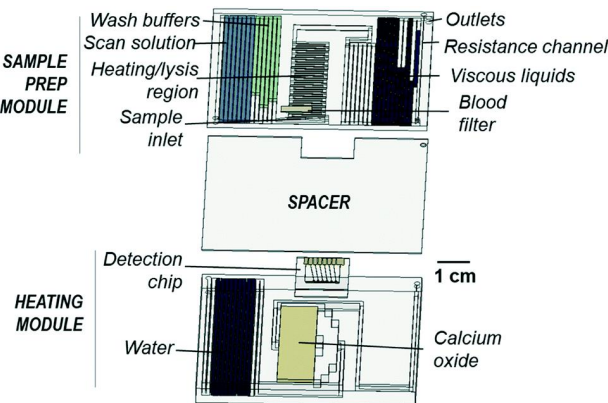

4) Hybridization 6) Scan
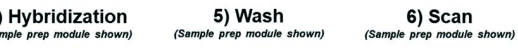

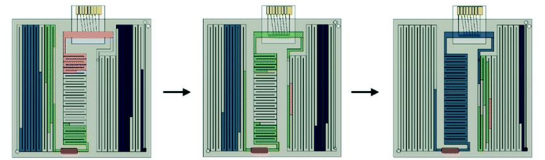

Figure 4: (A) An example of a fully integrated platform for DNA detection by Liu et al. (B) and (C) show a breakdown of the individual parts of the system and their functions. Reproduced from (Liu et al. 2018) with permission from The Royal Society of Chemistry. 
for biosensors. These techniques include polymerase chain reaction (PCR), loopmediated isothermal amplification (LAMP), and rolling circle amplification (RCA), which are routinely used in many DNA studies to increase the concentration of a specific DNA sequence. This naturally lends itself to DNA sensing and several groups have worked to integrate these processes on DNA detection chips (Liu et al., 2004). The Plaxco group, for example, developed a lab on a chip style sensor where the gold electrodes were fabricated on a glass wafer before being bonded to a PDMS microfluidic system, shown in figure 5 (Patterson et al., 2013). Using on-chip LAMP, the device was able to detect less than 10 aM of Salmonella DNA. They then successfully employed their device in measuring Salmonella present in blood samples taken from a murine mouse model, a significant step towards a true point-of care device, though the complexity inherent in the amplification process still presents a barrier to widespread use (Patterson et al., 2013). More recently they developed a method of quantifying the concentration of LAMP products in-situ. They remark that further improvements to systems such as theirs could be made through miniaturizing and automating sample preparation and integrating measurement electronics (Hsieh et al., 2015). Another example is Jha et al. who designed a point of care testing device which integrates cell lysis and PCR amplification in a microfluidic chamber, followed by electrochemical DNA detection (Jha et al., 2012). They present a LoD of $1 \mathrm{ng} / 35 \mu \mathrm{L}$ of Lambda phage DNA. To their credit, the authors go into detail about the disadvantages, as well as advantages, of their system including temperature variations of the thin film heater affecting the PCR and a lack of miniaturized pump. 


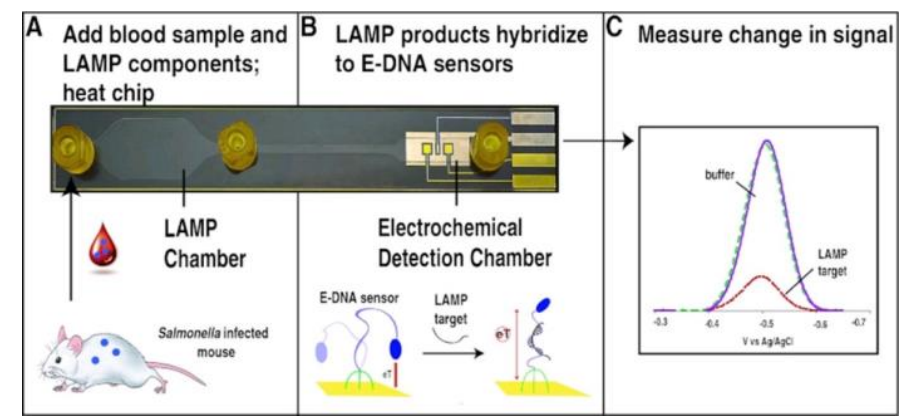

Figure 5: A salmonella sensor comprising microfluidic sample delivery, LAMP gene amplification, and detection electrodes. Reprinted from (Patterson et al., 2013) Copyright 2013 American Society for Microbiology.

\subsection{Indium Tin Oxide}

Indium Tin Oxide (ITO) is a conductive and transparent oxide, thin films of which have been used as an electrode material for biosensors, although less often than gold. The advantages of this type of film include its high stability, ease of combination with microfabrication processes, and relatively cheap cost compared with gold or platinum (Aydın and Sezgintürk, 2017). However, its major benefit is its optical transparency, enabling electrochemical methods to be combined with optical ones. A study by Moore et al. focusses on optimizing ITO surfaces for attachment of a DNA SAM and hybridization sensing (Moore et al., 2006). They arrive at an optimal deposition process for ITO with a low sheet resistance, high transparency, and high surface uniformity. They then demonstrate a combination of electrochemical and optical measurement techniques by characterizing DNA hybridization on a silane anchored SAM, using Fourier Transform Infra-Red Spectroscopy at the same time as cyclic voltammetry. The advantages of ITO are also utilized by Barreda-Garcia et al., who developed an optimized biosensor for detecting Salmonella (Barreda-García et al., 2017, 2018). They demonstrate isothermal gene amplification on the same surface as their sensor and were able to detect single molecules of the target. Interestingly, the authors mention the possibility of using the electrode itself for the heating steps in amplification procedures as ITO has widely been used as a thin film heating element. In fact, the on-chip PCR system by Jha et al., discussed in the previous section, uses a thin film ITO heater. Fu 
et al. used a triplex DNA probe on ITO electrodes to detect melamine (Fu et al., 2016). Abasic sites were deliberately inserted into the probe structure and enabled it to selectively recognize melamine with a LoD of $0.4 \mathrm{nM}$. ITO has demonstrated encouraging results for DNA detection and has also been used as an element in many other kinds of biosensor targeting proteins, bacteria, and antibodies (Bagbi et al., 2016; Pruna et al., 2018; dos Santos et al., 2015; Törer et al., 2018). This combined with its utility as a thin heating element and a substrate compatible with optical measurement techniques makes ITO a promising material for developing integrated sensing systems.

\subsection{Carbon}

Carbon has been used frequently as a biosensing electrode material because of its conductivity and chemical inertness. It most often features in literature in the form of carbon nanotubes or graphene/graphene oxide electrodes or electrode modifications. These materials, while fundamentally interesting and capable of some very impressive results, still struggle to be adapted for commercial use. Several example of groups trying overcome this problem exist and the authors are aware of one commercialized FET-based biosensor that employs graphene (Nanomedical Diagnostics; Campos et al., 2018; Li et al., 2003). Many reviews already exist on graphene and carbon nanotube based sensors, so they will not be discussed further here (Kumar et al., 2015; Yang et al., 2010). Thin film carbon is a more readily adaptable form of carbon for industry, though it has been used far less often due to the relative difficulty and cost of deposition. Carbon is usually deposited using chemical vapor deposition as diamond or diamondlike films. Diamond thin films used for biosensors typically employ boron as a dopant to increase conductivity, making boron doped diamond (BDD) a very attractive material due to its chemical inertness, giving it a very wide potential window and a highly robust and stable surface. This leads to one of the main challenges with boron doped diamond biosensors aside from its cost; attaching biological molecules to such an unreactive surface (Kondo et al., 2005; Svítková et al., 2016). Despite many examples of BDD biosensors in literature, especially immunosensors, there are relatively few DNA hybridization sensors. Weng et al. measured the hybridization of 
the oncogenic human p53 gene with a complementary ssDNA immobilized on polyethylenimine on the BDD surface without the use of redox agent in solution (Weng et al., 2008). Using EIS, they were able detect hybridization down to $10^{-19} \mathrm{~g} \mathrm{~mL}^{-1}$, at an optimal frequency of $10 \mathrm{~Hz}$. Virgilio et al. demonstrate the fabrication of an array of boron-doped diamond nanoelectrodes (Virgilio et al., 2013). Instead of functionalizing the boron doped diamond itself, the authors functionalize the polycarbonate insulator around the electrodes and show, using optical methods, that a SAM layer is present. No further electrochemical measurements, however, are reported.

Another method of deploying thin film carbon is through pyrolyzing photoresist (Kim et al., 1998; Scarfì et al., 2016). This involves depositing and patterning a layer of a light sensitive polymer called photoresist, which is used throughout the microfabrication process and subsequently carbonizing it at high temperature. This process has been used to produce patternable carbon electrodes for a number of applications including biosensors (Donner et al., 2006; Lee et al., 2008; Sharma et al., 2017). Groups such as the Kassegne group have deployed SAMs of DNA on pyrolized photoresist in order to characterize DNA as conductive, self-assembled nanowires (Hirabayashi et al., 2015). Despite this, there seems to be little interest in utilizing pyrolized photoresist for DNA hybridization sensing. An alternative approach to utilizing photoresist as an electrode film was presented by Benlarbi et al., who used SU8 photoresist doped with graphite to make it electrically conductive (Benlarbi et al., 2012). The authors were able to gain a satisfactory electrochemical response from the electrode without compromising the lithographic properties of the SU-8. The electrodes were then functionalized with probe DNA, although the detection of target hybridization was ascertained using chemiluminescent imaging rather than electrochemical measurements. 


\section{Miniaturisation}

\subsection{Microelectrodes}

It has long been known that microelectrodes offer many analytical advantages over macro-scale electrodes. The hemispherical diffusion profile typical of microelectrodes in combination with the small surface area of the sensor yields a higher signal to noise ratio, higher current density, and simpler analytical treatment for Faradaic processes (Bard et al., 1980; Corrigan et al., 2014; Forster, 1994; Stulík et al., 2000). Despite this, thin film microelectrodes are not as frequently used as DNA biosensors compared to macroelectrodes. A potential reason for this is due to the cost of manufacturing processes required to create reliable, sub 50 micrometer feature sizes. Microfabrication is therefore one of the most common methods of producing microelectrodes. Figure 6 shows a microfabricated microelectrode sensor produced by Rajapaksha et al. It comprises an array of thin film gold interdigitated electrodes (IDE)s $6 \mu \mathrm{m}$ wide and spaced $4 \mu \mathrm{m}$ apart (Rajapaksha et al., 2017). They used a method where the DNA was linked to aminosilane: (3-Aminopropyl) triethoxysilane (APTES), which was deposited in between the electrodes to create a conduction path between them. When the DNA hybridized, the increased negative charge outside the APTES layer increased the positive charges in the layer, resulting in a higher current. The LoD for E. Coli DNA was calculated as $0.8 \mathrm{fM}$. Zimdars et al. utilized a detection scheme with a DNA intercalator, which selectively bound to the DNA probe if it had hybridized with a target sequence. Assays were performed on 32 individually addressable microelectrodes and the lowest measured concentration of RNA was $30 \mathrm{fM}$ and $60 \mathrm{nM}$ of synthetic DNA (Zimdars et al., 2015).

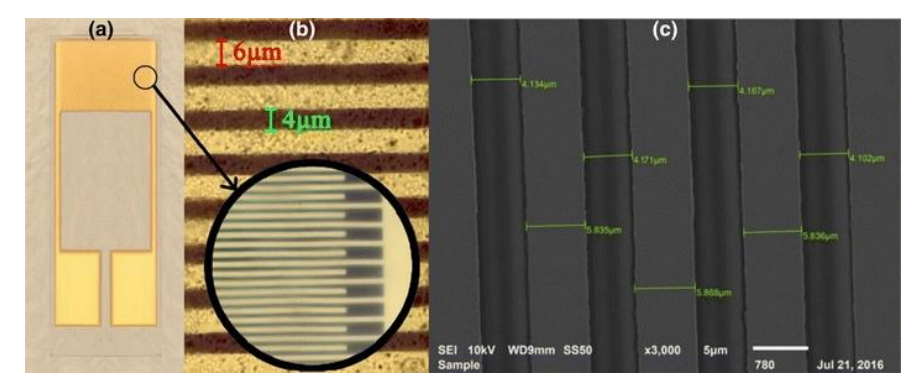


Figure 6: An interdigitated microelectrode array produced using photolithography. Reproduced from (Rajapaksha et al., 2017) with permission from Microsystems Technology, Springer Nature.

A novel approach to microelectrode fabrication was demonstrated by MedinaSánchez et al, who fabricated rolled-up thin film gold electrodes (Medina-Sánchez et al., 2016). They applied a technique where a strained thin film is deposited over a sacrificial layer. Gold microelectrodes were then fabricated on top and after the sacrificial layer was removed, the strained film rolled up as demonstrated in figure 7. A LoD of 20 aM was achieved when detecting H1N1 AIV DNA without any amplification or labelling of the target, or surface modification of the electrode. It is noteworthy that the planar control microelectrode was shown to detect to $2 \mathrm{pM}$.

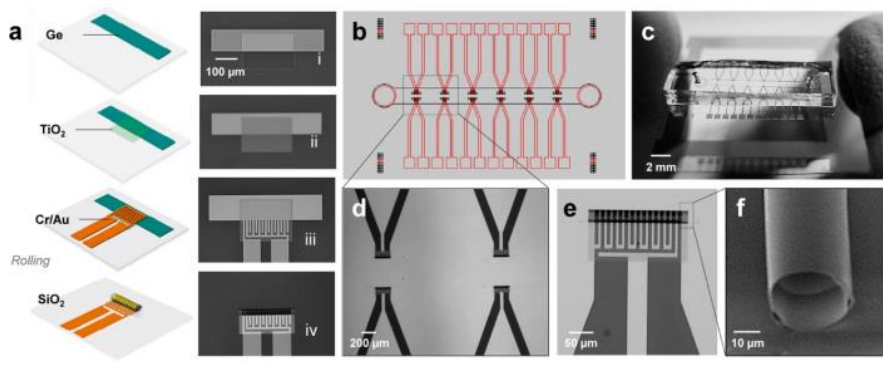

Figure 7: Rolled-up interdigitated microelectrodes employed in a PDMS microfluidic channel and used to detect H1N1 DNA. Reproduced with permission from (MedinaSánchez et al., 2016). Copyright (2016) American Chemical Society.

Previous work by Li et al. (including author DC) used microfabricated platinum microelectrodes to detect MRSA using EIS (Li et al., 2017). Microelectrodes of different radii were investigated to find an optimal size for detection, as well as determine fundamental differences between macro and micro-scale biosensors. The change in signal after hybridization in $100 \mathrm{nM}$ synthetic MRSA DNA was observed to increase with decreasing electrode size, and the largest change was obtained from the smallest microelectrode size (5 $\mu \mathrm{m}$ radius). As expected, the EIS response fundamentally changed between macro and microelectrodes because of the enhanced mass transport at the microelectrode surface. Slinker et al. also investigated electrodes of different sizes for multiplexed DNA detection (Slinker et al., 2010). They found that the thin film on-chip electrodes performed better, with higher charge transfer, than a 
rod electrode. Additionally, they briefly investigated electrodes of diameters 300, 56, and $10 \mu \mathrm{m}$. The smallest were found to demonstrate the expected microelectrode response, which gave improved DNA detection, although little analysis of this is presented.

Arrays of gold microelectrodes were employed by Li et al to detect single base-pair mismatches in simple and complex media (Li et al., 2006). They were successfully able to detect these single base pair mismatches down to $10 \mathrm{fM}$ in a solution of potassium ferri- and ferrocyanide with TRIS- $\mathrm{ClO}_{4}$ as a supporting electrolyte. They noted that when the sensor was used in more complex bovine serum albumin, the LoD increased to $1 \mathrm{pM}$. Despite the benefits of micro-scale electrodes, challenges with measuring DNA hybridization using microelectrodes have been encountered including inconsistent SAM layer formation, with it being necessary to modify the SAM forming conditions to achieve consistent film formation on small electrodes, and difficulties associated with interpreting the impedance behavior at a DNA modified microelectrode, i.e. selecting an appropriately sized electrode and suitable equivalent circuit to fit the response (Corrigan et al., 2018; Li et al., 2017). Additionally, factors which are not normally a problem for bulk gold electrodes can present an issue for thin film devices. For example, the ferri/ferrocyanide redox couple has been observed to etch gold layers (Vogt et al., 2016).

\subsection{Nanoelectrodes}

As electrode dimensions are reduced from the micro-scale to the nanoscale, factors such as signal to noise ratio and current density further improve (Arrigan, 2004; Schmueser et al., 2013). Despite the challenges in fabricating reproducible and reliable nanoelectrodes, several groups have demonstrated their application to biosensing (Soraya et al., 2018; Sultana et al., 2014; Miranda-Castro et al., 2018; Terry et al., 2013). Finot et al. also used interdigitated gold nanoelectrodes and compared their sensitivity to both macro and microelectrodes (Finot et al., 2003). They found the nanoelectrodes to be significantly more sensitive when detecting oligonucleotides using hexaammineruthenium (III) as a redox couple. Bonanni et al. took advantage of this 
improved sensitivity by using a fabricated array of interdigitated gold nanoelectrodes to detect single base mutations in a breast cancer gene (Bonanni et al., 2010). EIS was used as a detection method, along with a sandwich probe assay and gold nanoparticles for signal amplification. Triroj et al. used a focused ion beam to mill a nanoelectrode array and used it as a sensing system in a full detection platform with on-chip counter electrode, reference electrode, and microfluidic system (Triroj et al., 2011). Although this was used to detect antigens rather than DNA sequences, it demonstrates the capability to manufacture a full biosensor system with nanoelectrodes and microfluidics which could be adapted for DNA sensing. Despite promising results, the challenge of microfabricated nanoelectrodes for DNA biosensing lies in their manufacture and are hence not commonly used.

\subsection{On-Chip Biosensors}

There have been a few papers reporting DNA sensors on CMOS chip substrates. These typically comprise a measurement electronics die fabricated in a commercial foundry, which has been post-processed to open electrodes on the surface of the chip (Yusof and Kazuo, 2014). Since most foundries only work with standard semiconductor metals such as copper or aluminum, electrochemically compatible materials like gold or platinum must be deposited and patterned in-house. This was the case for Jafari et al, who electroplated both gold planar and nanostructured microelectrodes onto a CMOS die (Jafari et al., 2012, 2014). DNA hybridization was detected using cyclic voltammetry and a LoD of $100 \mathrm{nM}$ and $10 \mathrm{aM}$ respectively were found for each electrode type. Levine et al. also employed gold as an electrode metal during postprocessing of their CMOS die (Levine et al., 2009). They fabricated an array individually addressable electrodes which enabled them to perform simultaneous, multiplexed measurements of two separate target sequences on-chip. The chip is presented in figure 8 and the lowest concentration measured was $4 \mathrm{nM}$, although theoretically the chip could measure down to $50 \mathrm{pM}$. Interestingly, this limit is imposed by the limitations of the on-chip electronics and not necessarily the DNA detection 
scheme. Manickam et al. employed the electroless plating process ENIG (electroless nickel, immersion gold) to form gold electrodes on foundry dies. First nickel and then gold are chemically plated onto exposed metal (Manickam et al., 2010). They used these electrodes to detect DNA hybridization using EIS. Again a theoretical LoD, based on the limits of the on-chip electronics, was presented as $6.25 \times 10^{-9}$ molecules $/ \mathrm{cm}^{2}$.

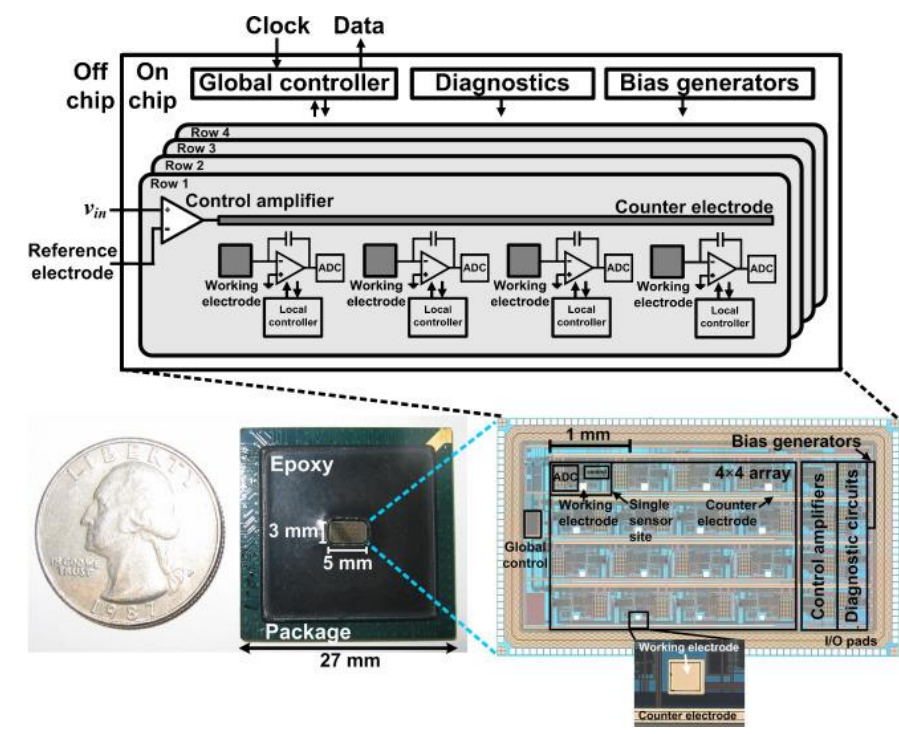

Figure 8: A CMOS potentiostat chip with post processed electrodes on the surface.

Bottom left shows the chip after packaging in epoxy, ready for measurements.

Reprinted from (Levine et al., 2009) Copyright 2009 Elsevier.

\subsection{Packaging}

Packaging a microfabricated die is an important component in its final usage. Materials such as epoxies, polymers, and resins are generally used for this (Datta et al., 2004). For a sensor which requires intimate contact with its environment, such as those detailed above, this coating must be patterned while retaining its adhesive and barrier properties. This can be achieved by lithographically patterning, molding or constructing the packaging first before bonding it to the chip (Buchoux et al., 2017; Li et al., 2011). However, in the case of a point of care biosensor it would be desirable to incorporate microfluidics into the packaging solution, integrating the ability to manipulate the 
sample solution with the measurement. This requires capillaries, reservoirs, and inlet/outlets to transport liquids, as well as the usual encapsulation of exposed wire bonds and pads. Most commonly this takes the form of PDMS microchannels formed using soft-lithography, which are bonded to the chip substrate using an oxygen plasma pre-treatment. This can include integrated valves, such as those designed by Ben-Yoav et al., or heating electrodes which allow for cell lysis or DNA melting. Other polymers have been used such as PMMA, Paralyene-C, or polyimide. This has been exploited by several groups to incorporate on-chip gene amplification, such as those described above. One of the bigger challenges is the miniaturization of pumps and valves which limit lab on a chip style integrated systems.

From a manufacturing point of view, chip assembly and packaging is often the most expensive and labor intensive process step. The inclusion of further complexities such as microfluidic channels, reservoirs, and compatibility with pumps could prove challenging. Such a system would also likely require sterilization and it is unclear which approach would be most compatible with the chip and microfluidic system. One of the most common methods is autoclaving, which requires exposing the system to steam around $120^{\circ} \mathrm{C}$. This could damage the packaging and, if exposed, corrode metal layers on the die (Datta-Chaudhuri et al., 2016). A more suitable technique may be chemicalbased, such as ethylene oxide gas or ethanol (Datta-Chaudhuri et al., 2016; Dias et al., 2009; Birmele., 2006). Irradiation by gamma rays and ultraviolet light have been previously reported for electrochemical enzyme-based biosensors (Lin and Hsu, 2011; Sharma et al., 2016; von Woedtke et al., 2002; Abel et al., 1999). However, the stability of DNA-based capture films under these conditions is uncertain and such radiation also risks trapping charge in semiconductor layers, potentially causing failure of any onchip CMOS electronics (Birkholz et al., 2016; Sharma et al., 2016; Gouker et al., 2009; Fleetwood et al., 1988). Interestingly, Oberländer et al. demonstrated online monitoring of sterilization efficacy using microfabricated interdigitated microelectrodes (Oberländer et al., 2015). This hints at the possibility of using a second electrochemical sensor, integrated onto the biosensor chip, to provide characterization and quality control for sterilizing point-of-care biosensors. 


\section{Electrochemical Measurement Methods}

\section{$3.1 \quad E I S$}

When implementing a microfabricated electrochemical biosensor system it is possible to utilize the same electroanalytical techniques employed for macro scale devices and electrodes produced using other approaches, e.g. screen printing. For microelectrode and nanoelectrodes the expectation is that enhanced sensitivity will be achieved through the favorable electro-analytical properties which arise from employing electrode sensors with such small dimensions. EIS is a versatile and sensitive electrochemical technique which has found applications across a range of areas, including battery development, corrosion monitoring, and label free detection of biological binding, including detection of DNA sequences. The technique works by applying alternating current (AC) excitations of varying frequency to the potential of the working electrode and measuring the resulting current. It is possible to model this response as an electrical circuit comprising elements such as the solution resistance $\left(R_{S}\right)$, the double layer capacitance $\left(C_{D L}\right)$ and the charge transfer resistance $\left(R_{C T}\right)$. In biosensing applications, $C_{D L}$ and $R_{C T}$ are often employed as the key parameter used to quantify change brought about by DNA hybridization or the presence of DNA target molecules in a sample. Informative reviews on the use of EIS for DNA biosensing have been published before and set out a number of important considerations (Lisdat and Schäfer, 2008; Park and Park, 2009).

Examples of EIS based sensing using microfabricated sensor systems include the label free DNA sensor based on a DNA modified boron-doped diamond electrode discussed above, through use of alumina nanopore membranes, and an integrated microfluidic system and microelectrode array for detection of DNA hybridization in point of care settings (Weng et al., 2008; Wu et al., 2015; Ben-Yoav et al., 2017). It has been established for gold surfaces that Faradaic and non-Faradaic EIS measurements can yield approximately equal sensitivity and so it is possible to dispense with a redox couple all together. In fact non-Faradaic EIS measurements have shown the $C_{D L}$ can be used with interdigitated gold electrodes to achieve attomolar sensitivity levels for DNA detection and that voltage pulses and the resulting non-Faradaic currents can be used to 
measure DNA hybridization in the pM to nM range (Fernandes et al., 2014; Hsu et al., 2016; Wang et al., 2017). Owing to the sensitivity of EIS, the placement of the reference electrode can affect the response (Dimaki et al., 2014). This lends microfabricated systems an advantage as the reference electrode can be fabricated on-chip resulting in consistent inter-electrode distances between measurements and between devices. Despite its enhanced sensitivity and capacity for label-free measurements, an EIS response can be difficult to interpret and the analysis does not lend itself well to automation. As such, point-of-care devices employing EIS would likely require a skilled operator or custom written analysis software to correctly interpret the EIS response and fit the equivalent circuit elements accurately.

\subsection{Differential Pulse Voltammetry (DPV)}

DPV is a derivative of linear sweep or staircase voltammetry. The measurement consists of a series of potential pulses, with each pulse being fixed and of small amplitude (10 to $100 \mathrm{mV}$ ) and superimposed on a slowly changing base potential. The working electrode current is measured at two points for each pulse, the first point just before the application of the pulse and the second at the end of the pulse. These sampling points are selected to allow for the decay of the non-Faradaic current and thus eliminating contributions from background effects, such as double layer charging and parasitic capacitances (a common issue in microfabricated devices). The difference between the measured currents at the two pulse points is determined and plotted against the base potential. The peak current can be indicative of the presence of a redox marker such as the ferri/ferrocyanide redox couple, which is commonly employed in DNA biosensing. Examples of sensitive DNA detection systems involving this approach include detection of plant pathogen DNA using isothermal amplification in combination with a gold nanoparticle reporter, detection of DNA sequences relevant to Mycobacterium Tuberculosis using a gold surface functionalized with thiol modified DNA sequences, and E.coli DNA detection using a graphene oxide-chitosan composite decorated with nickel ferrite nanoparticles to achieve $10^{-16} \mathrm{M}$ sensitivity (Gaffar et al., 
2017; Lau and Botella, 2017; Tiwari et al., 2015). DPV has been used to achieve 2.3 pM sensitivity for DNA hybridization when a methylene blue tagged hairpin probe DNA film was immobilized using assisted potential deposition and in similar work a LoD of $3.4 \mathrm{pM}$ was discovered for a ferrocene tagged DNA probe deployed in a similar configuration (Hong et al., 2017; Kong et al., 2018). Finally, simultaneous detection of Legionella and Legionella pneumophila was achieved by using a signal-off double DNA probe electrochemical sensor with ferrocene and methylene blue hairpin probes where signal changes arise through specific cleavage of restriction sites within the probe sequences (Li et al., 2017). The advantages of a DPV measurement is its speed, relative sensitivity, and ease of analysis.

\subsection{Square Wave Voltammetry (SWV)}

The excitation signal in SWV consists of a symmetrical square-wave pulse of amplitude superimposed on a staircase waveform where the forward pulse of the square wave coincides with the staircase step. The net current is obtained by taking the difference between the forward and reverse currents and is centered on the redox potential in the resulting plot of current vs potential. The peak height is directly proportional to the concentration of the electroactive species and direct detection limits as low as $10^{-9} \mathrm{M}$ are possible for a solution based reversible redox couple. Like DPV, the technique has several advantages, including its excellent sensitivity and rejection of background currents. A key advantage is speed, which when coupled with computer control and signal averaging, allows for experiments to be performed repetitively to increase the signal to noise ratio. Applications of SWV include the study of electrode kinetics with regard to preceding, following, or catalytic homogeneous chemical reactions, determination of some species at trace levels, and its use with electrochemical detection in high-performance liquid chromatography (HPLC) and biosensing for a range of analytes. In terms of work involving DNA detection using microfabricated systems, this technique is still in its relative infancy. However, there are reports which look at development of assays for DNA sequences, establish the optimum parameters 
for the SWV measurement and involve the use of a redox tagged DNA probe in order to generate the Faradaic signal (Cao et al., 2014). More specifically, binding energies, hybridization temperature and SWV parameters were assessed to find the optimum conditions for detecting short oligonucleotides (Somasundaram et al., 2018). Also, the signal gain of microfabricated gold DNA sensor systems in square wave mode was assessed with the optimal square-wave frequency depending on the structure of the probe, the nature of the redox reporter, and other features of the sensor (DauphinDucharme and Plaxco, 2016). Establishing the relative importance of these parameters is crucial to the development and widespread implementation of SWV as a reliable measurement technique for DNA hybridization. 


\begin{tabular}{|c|c|c|c|c|c|}
\hline Author & Year & $\begin{array}{c}\text { Electrode } \\
\text { Size/Geometry } \\
(\mathbf{m})\end{array}$ & Target & Measurement & LoD (M) \\
\hline (Soraya et al., 2018) & 2018 & $\mathrm{IDE}_{7}^{-1 \times 10^{-}}$ & $\begin{array}{l}\text { Human samples of human leukocyte } \\
\text { antigen }\end{array}$ & EIS & Not stated* \\
\hline (Hong et al., 2018) & 2018 & D $-4 \times 10^{-4}$ & GSTP1 and EFEMP1 spiked in urine & DPV & $20 \times 10^{-12}$ \\
\hline (Ianeselli et al., 2014) & 2014 & D $-1 \times 10^{-4}$ & Complimentary synthetic DNA & EIS & $100 \times 10^{-12} *$ \\
\hline (P. Li et al., 2017) & 2016 & D $-1 \times 10^{-4}$ & Complimentary synthetic DNA & EIS & $1 \times 10^{-12}$ \\
\hline (García et al., 2012) . & 2012 & D $-4 \times 10^{-3}$ & Salmonella & DPV & $208 \times 10^{-9}$ \\
\hline (Matharu et al., 2017) & 2017 & $\begin{array}{l}\mathrm{D}-3.87 \times \\
10^{-3}\end{array}$ & Complimentary synthetic DNA & SWV & $50 \times 10^{-9} \#$ \\
\hline (Berdat et al., 2007) & 2008 & $\underset{3}{\mathrm{IDE}}-5 \times 10^{-}$ & $\begin{array}{l}\text { Complimentary synthetic } \\
\text { DNA/Salmonella }\end{array}$ & EIS & $1-10 \times 10^{-9}$ \\
\hline (Koydemir et al., 2014) & 2014 & D $-1 \times 10^{-3}$ & MRSA & DPV & $10 \times 10^{-12 *}$ \\
\hline (Horny et al., 2016) & 2016 & B $-3 \times 10^{-5}$ & Complimentary synthetic DNA & $\mathrm{CVs}$ & $1 \times 10^{-18}$ \\
\hline (Ben-Yoav et al., 2015) & 2015 & D $-1 \times 10^{-4}$ & Complimentary synthetic DNA & EIS & $1 \times 10^{-9}$ \\
\hline (Ferguson et al., 2009) & 2009 & B $-2.5 \times 10^{-4}$ & Salmonella & $\mathrm{ACV}$ & $<10 \times 10^{-18}$ \\
\hline (Rho et al., 2008) & 2008 & $\mathrm{~S}-\underset{2}{1.45 \times 10^{-}}$ & Complimentary synthetic DNA & $\mathrm{CVs}$ & $1.5 \times 10^{-6 * \#}$ \\
\hline (Liu et al., 2004) & 2004 & D - Macro & E. coli & $\mathrm{ACV}$ & Not stated \\
\hline (Barreda-García et al., 2018) & 2018 & D $-2 \times 10^{-3}$ & Salmonella & DPV & $\begin{array}{l}50 \text { Genomic } \\
\text { units per } \mu \mathrm{L}\end{array}$ \\
\hline (Campos et al., 2018) & 2018 & D $-4 \times 10^{-5}$ & Complimentary synthetic DNA & EIS & $5 \times 10^{-12 *}$ \\
\hline (Weng et al., 2008) & 2008 & Macro & Complimentary synthetic Oligos & EIS & $10 \times 10^{-19} \mathrm{~g} / \mathrm{ml}$ \\
\hline (Rajapaksha et al., 2017) & 2017 & $\mathrm{IDE}_{6}-6 \times 10^{-}$ & E. coli synthetic Oligos & IV curve & $800 \times 10^{-18}$ \\
\hline $\begin{array}{l}\text { (Medina-Sánchez et al., } \\
\text { 2016) }\end{array}$ & 2016 & $\underset{5}{\mathrm{IDE}}-1 \times 10^{-}$ & H1N1 & EIS & $20 \times 10^{-18 *}$ \\
\hline (P. Li et al., 2017) & 2017 & D $-1 \times 10^{-5}$ & MRSA Oligo & EIS & $100 \times 10^{-9 * \#}$ \\
\hline (Jafari et al., 2014) & 2014 & S - $2 \times 10^{-6}$ & Complimentary synthetic Oligos & $\mathrm{CVs}$ & $10 \times 10^{-18}$ \\
\hline (Levine et al., 2009) & 2009 & S $-1 \times 10^{-4}$ & Complimentary synthetic Oligos & $\mathrm{CVs}$ & $4 \times 10^{-9 *}$ \\
\hline $\begin{array}{l}\text { (Manickam et al., 2010) } \\
\text { (Fu et al., 2016) }\end{array}$ & $\begin{array}{l}2010 \\
2016\end{array}$ & $\begin{array}{l}\text { S }-4 \times 10^{-5} \\
\text { B }-3 \times 10^{-3}\end{array}$ & $\begin{array}{l}\text { Complimentary synthetic Oligos } \\
\text { Melamine }\end{array}$ & DPV & $\begin{array}{r}6.25 \times 10^{-9} \\
\text { molecules } / \mathrm{cm}^{2} \\
400 \times 10^{-12}\end{array}$ \\
\hline (Li et al., 2006) & 2004 & D $-1 \times 10^{-5}$ & Complimentary synthetic Oligos & EIS & $10 \times 10^{-15}$ \\
\hline
\end{tabular}

IDE-x: IDE of finger width $x$ D-x: Disc of diameter $\mathrm{x}$ S-x: Square of edge length $x$

B-x: Band of width $\mathrm{x}$

* Lowest concentration measured

" Sensitivity not challenged

Table 2: A comparison of select works in literature, comparing factors such as the electrode size, measurement target, measurement method, and limit of detection. 


\section{Summary and Conclusions}

Table 2 presents a selection of thin film biosensors from literature, showing aspects of their design, performance, and characterization. These examples demonstrate that thin film DNA biosensors have attained a whole range of sensitivities and performances in complex and simple media. It is important to remember that comparisons between these sensors must be done carefully as they fulfill a myriad of different functions with differing requirements (indeed a recent piece by the editorial board of ACS Sensors discussed the reporting and reproducibility standards in the field of sensors (Gooding et al., 2017)). However, some commonality is found in many of these systems being built around a sputtered or evaporated gold macroelectrode. For most applications the sensitivity of such a system needs improving and many strategies are used to enhance the sensor's performance. These can include: altering the surface of the electrode, labelling the target, and using gene amplification. Additionally, the comparisons in table 2, and this review on the whole, suggest that miniaturizing the sensing element can also be an effective strategy for enhancing sensitivity. Despite this, all of these methods have their own challenges when it comes to developing a final, manufacturable point-of-care device.

\section{Future Perspectives}

One particularly obvious difficulty for future mass production of electrochemical DNA biosensors highlighted by Barbaro et al., is that most utilize metals such as gold, platinum, or silver (Barbaro et al., 2012). This can be a problem for scaling up their manufacture as these materials are incompatible with CMOS foundry fabrication. This is demonstrated by the many groups who have CMOS chips fabricated in an external foundry, and then must apply materials such as these in-house using post-processing techniques. Although this is acceptable for research it raises the question of whether the manufacture of these devices can be properly scaled up, as post-processing can be challenging to do en-mass. Some groups have explored switching more commonly used electrochemical materials for CMOS compatible ones, which requires the development and characterization of new detection methods (Barbaro et al., 2012; Lobert et al., 
2003). Another approach may be to have the CMOS circuitry and sensor fabricated as separate modules, which can be combined. This enables the sensors to be fabricated in

\footnotetext{
Abel, P., von Woedtke, T., Schulz, B., Bergann, T., Schwock, A., 1999. . Journal of Molecular Catalysis B: Enzymatic 7, 93 - 100.

Arlett, J.L., Myers, E.B., Roukes, M.L., 2011. . Nature Nanotechnology 6, 203-215.
} 
Aydın, E., Sezgintürk, M., 2017. . TrAC Trends in Analytical Chemistry 97, 309 315.

Bagbi, Y., Sharma, A., Bohidar, H.B., Solanki, P.R., 2016. . International Journal of Biological Macromolecules 82, 480 - 487.

605 Barbaro, M, Caboni, A, Loi, D, Lai, S, Homsy, A, van der Wal, P.D., de Rooij, N.F., 2012. . Sensors and Actuators B: Chemical 171-172, 148 - 154.

Bard, A.J., Faulkner, L.R., Leddy, J., Zoski, C.G., Electrochemical Methods:

Fundamentals and Applications, Wiley, New York, NY, 1980.

Barreda-García, S, Miranda-Castro, R, de-los-Santos-Álvarez, N, Miranda-Ordieres,

610 AJ, Lobo-Castañón, MJ, 2017. . Chem. Commun. 53, 9721-9724.

Barreda-García, S., Miranda-Castro, R., de-los-Santos-Álvarez, N., Lobo-Castañón, M., 2018. . Sensors and Actuators B: Chemical 268, 438 - 445.

Bartosik, M., Jirakova, L., 2019. . Current Opinion in Electrochemistry 14, 96 - 103. Benlarbi, M., Blum, L.J., Marquette, C.A., 2012. . Biosensors and Bioelectronics 38, $615220-225$.

Ben-Yoav, H., Dykstra, P.H., Bentley, W.E., Ghodssi, R., 2015. . Biosensors and Bioelectronics 64, $579-585$.

Ben-Yoav, H., Dykstra, P.H., Bentley, W.E., Ghodssi, R., 2017. Microfluidic Arrayed Lab-On-A-Chip for Electrochemical Capacitive Detection of DNA Hybridization

620 Events, in: Prickril, B., Rasooly, A. (Eds.), Biosensors and Biodetection: Methods and Protocols, Volume 2: Electrochemical, Bioelectronic, Piezoelectric, Cellular and Molecular Biosensors. Springer New York, New York, NY, pp. 71-88.

Berdat, D., Rodríguez, A.C., Herrera, F., Gijs, M.A., 2007. . Lab on a Chip 8, $302-$ 308.

625 Birmele, M., Roberts, M., Garland, J., 2006. . Journal of Microbiological Methods 67, $619-623$.

Blair, EO, Corrigan, DK, Terry, JG, Mount, AR, Walton, AJ, 2015. . Journal of Microelectromechanical Systems 24, 1346-1354.

Blair, E.O., Basanta, L.P., Schmueser, I., Marland, J.R.., Buchoux, A., Dunare, C.,

630 Normand, M., Stokes, A.A., Walton, A.J., Smith, S., 2018 IEEE International Conference on Microelectronic Test Structures (ICMTS) 179-184.

Bonanni, A., Fernández-Cuesta, I., Borrisé, X., Pérez-Murano, F., Alegret, S., del Valle, M., 2010. . Microchimica Acta 170, 275-281.

Buchoux, A., Blair, E.O., Tsiamis, A., Marland, J.R.., Smith, S., 2017. Symposium on

Design, Test, Integration and Packaging of MEMS/MOEMS (DTIP).

Campos, R, Machado, G, Cerqueira, M.F., Borme, J, Alpuim, P, 2018.

Microelectronic Engineering 189, 85 - 90.

Cao, H.T., Pham, X.T., Ha, V.L., Le, V.H., 2014. Advances in Natural Sciences:

Nanoscience and Nanotechnology 5.

640 Capaldo, P., Alfarano, S., Ianeselli, L., Zilio, S., Bosco, A., Parisse, P., Casalis, L., 2016. . ACS Sensors 1, 1003-1010.

Casteleijn, M.G., Richardson, D., Parkkila, P., Granqvist, N., Urtti, A., Viitala, T., 2018. Colloids and Surfaces A: Physicochemical and Engineering Aspects 539, 261 $-272$.

645 Choi, J., Lim, J., Lee, J., Kim, K., 2007. . Nanotechnology 18, 055603. Corrigan, D.K., Blair, E.O., Terry, J.G., Walton, A.J., Mount, A.R., 2014. . Analytical Chemistry 86, 11342-11348. 
Corrigan, D.K., Vezza, V., Schulze, H., Bachmann, T.T., Mount, A.R., Walton, A.J., Terry, J.G., 2018. . Sensors 18.

650 Daggumati, P., Matharu, Z., Seker, E., 2015. . Analytical Chemistry 87, 8149-8156. Datta, M., Osaka, T., Schultze, W.J., 2004. Microelectronic packaging, New Trends in Electrochemical Technology. CRC press.

Dauphin-Ducharme, P., Plaxco, K.W., 2016. . Analytical Chemistry 88, 1165411662.

655 Davis, F., Higson, S., 2005. . Biosensors and Bioelectronics 21, $1-20$.

Dias, F.N., Ishii, M., Nogaroto, S.L., Piccini, B., Penna, T.C., 2009. . Journal of Biomedical Materials Research Part B Applied Biomaterials 91B, 626-630.

Diculescu, V., Paquim, A.-M., Brett, A., 2005. . Sensors 5, 377-393.

Dimaki, M., Vergani, M., Heiskanen, A., Kwasny, D., Sasso, L., Carminati, M.,

660 Gerrard, J.A., Emneus, J., Svendsen, W.E., 2014. . Sensors 14, 9505-9521.

Donner, S., Li, H.-W., Yeung, E.S., Porter, M.D., 2006. . Analytical Chemistry 78, 2816-2822.

Drummond, G.T., Hill, M.G., Barton, J.K., 2003. . Nature Biotechnology 21.

Díaz-Serrano, M., Rosado, A., del Pilar, J., Arias, M., Guadalupe, A.R., 2011. . Electroanalysis 23, 1830-1841.

Ferapontova, E.E., 2017. . Current Opinion in Electrochemistry 5, 218 - 225.

Ferguson, B.S., Buchsbaum, S.F., Swensen, J.S., Hsieh, K., Lou, X., Soh, T.H., 2009. . Analytical Chemistry 81, 6503-6508.

Fernandes, F., Santos, A., Martins, D.C., Góes, M.S., Bueno, P.R., 2014. . Biosensors and Bioelectronics 57, $96-102$.

Ferrier, D.C., Shaver, M.P., Hands, P., 2015. . Biosensors and Bioelectronics 68, 798 -810 .

Finot, E., Bourillot, E., Meunier-Prest, R., Lacroute, Y., Legay, G., Cherkaoui-Malki, M., Latruffe, N., Siri, O., Braunstein, P., Dereux, A., 2003. . Ultramicroscopy 97, 441 $675-449$.

Fleetwood, DM, Winokur, PS, Schwank, JR, 1988. . IEEE Transactions on Nuclear Science 35, 1497-1505.

Forster, RJ, 1994. . Chemical Society Reviews.

Fu, C., Liu, C., Li, Y., Guo, Y., Luo, F., Wang, P., Guo, L., Qiu, B., Lin, Z., 2016. .

680 Analytical Chemistry 88, 10176-10182.

Gaffar, S., Nurmalasari, R., Yohan, Hartati, Y.W., 2017. . Procedia Technology 27, $74-80$.

García, T, Revenga-Parra, M, Añorga, L, S.Arana, Pariente, F, Lorenzo, E, 2012. Sensors and Actuators B: Chemical 161, 1030 - 1037.

685 George, J., Antony, A., Mathew, B., 2018. . Microchimica Acta 185.

Gooding, J.J., Bakker, E., Kelley, S., Long, Y., Merkx, M., Sailor, M., Tao, N., 2017. . ACS Sensors 2, 1377-1379.

Gouker, PM, Gadlage, MJ, McMorrow, D, McMarr, P, Hughes, H, Wyatt, P, Keast, C, Bhuva, BL, Narasimham, B, 2009. . IEEE Transactions on Nuclear

690 Science 56, 3477-3482.

Grieshaber, D., MacKenzie, R., Vörös, J., Reimhult, E., 2008. . Sensors 8, 14001458 .

Hansen, K.M., Thundat, T., 2005. . Methods 37, 57 - 64. 
Hirabayashi, M., Mehta, B., Nguyen, B., Kassegne, S., 2015. . Microsystem Technologies 21, 2359-2365.

Homola, J., 2003. . Analytical and Bioanalytical Chemistry 377, 528-539.

Hong, N., Cheng, L., Wei, B., Chen, C., He, L., kong, D., Ceng, J., Cui, H.-F., Fan, H., 2017. . Biosensors and Bioelectronics 91, $110-114$.

Hong, S.A., Kim, Y.-J., Kim, S., Yang, S., 2018. . Biosensors and Bioelectronics 107, $700 \quad 103-110$.

Horny, M.-C., Lazerges, M, Siaugue, J.-M., Pallandre, A, Rose, D, Bedioui, F, Deslouis, C, Haghiri-Gosnetd, A.-M., Gamby., J, 2016. . Lab on a Chip 16, 343734381.

Howorka, S., Cheley, S., Bayley, H., 2001. . Nature Biotechnology 19, 636-639.

Hsieh, K., Ferguson, S.B., Eisenstein, M., Plaxco, K.W., Soh, T.H., 2015. . Accounts of Chemical Research 48, 911-920.

Hsu, C.-P., Huang, Y.-F., Wang, Y.-L., 2016. . ECS Journal of Solid State Science and Technology 5, Q149-Q154.

Ianeselli, L., Grenci, G., Callegari, C., Tormen, M., Casalis, L., 2014. . Biosensors

710 and Bioelectronics 55, $1-6$.

Jafari, H, Soleymani, L, Genov, R, 2012. . IEEE Transactions on Biomedical Circuits and Systems 6, 468-478.

Jafari, HM, Abdelhalim, K, Soleymani, L, Sargent, EH, Kelley, SO, Genov, R, 2014. . IEEE Journal of Solid-State Circuits 49, 1223-1241. Jha, S., Chand, R., Han, D., Jang, Y.-C., Ra, G.-S., Kim, J., Nahm, B.-H., Kim, Y.-S., 2012. . Lab on a Chip 12, 4455-4464.

Kassal, P., Steinberg, M.D., Steinberg, I., 2018. . Sensors and Actuators B: Chemical 266, $228-245$.

Kim, J, Song, X, Kinoshita, K, Madou, M, White, R, 1998. . Journal of The

720 Electrochemical Society 145, 2314-2319.

Kindlundh, MG., Norlin, P., 2003. . The 12th International Conference on Solid-State Sensors, Actuators and Microsystems

Kondo, T., Honda, K., Tryk, D.A., Fujishima, A., 2005. . Journal of The Electrochemical Society 152, E18-E23.

725 Kong, D., Liao, F., Lin, Y., Cheng, L., Peng, H., Zhang, J., Cui, H., Hong, N., Chen, C., Wei, G., Fan, H., 2018. . Sensors and Actuators B: Chemical 266, 288 - 293.

Koydemir, HC, Kulah, H, Alp, A, Uner, AH, Hascelik, G, Ozgen, C, 2014. . IEEE Sensors Journal 14, 1844-1851.

Kumar, S., Tripathy, S., Jyoti, A., Singh, S., 2019. . Biosensors and Bioelectronics

$730 \quad 124-125,205-215$.

Kumar, S., Ahlawat, W., Kumar, R., Dilbaghi, N., 2015. . Biosensors and

Bioelectronics 70, $498-503$.

Lafleur, J.P., Jönsson, A., Senkbeil, S., Kutter, J.P., 2016. . Biosensors and Bioelectronics 76, $213-233$. Lau, Y.J., Botella, J.R., 2017. . Scientific Reports 7.

Lee, J.A., Hwang, S., Kwak, J., Park, S., Lee, S.S., Lee, K.-C., 2008. . Sensors and Actuators B: Chemical 129, $372-379$.

Levine, P.M., Gong, P., Levicky, R., Shepard, K.L., 2009. . Biosensors and Bioelectronics 24, 1995 - 2001. 
Li, J., Ng, H., Cassell, A., Fan, W., Chen, H., Ye, Q., Koehne, J., Han, J., Meyyappan, M, 2003. . Nano Letters 3, 597-602.

Li, L., Liu, X., Qureshi, W.A., Mason, A.J., 2011. . IEEE Transactions on Biomedical Circuits and Systems 5, 439-448.

Li, P., Piper, A., Schmueser, I., Mount, A.R., Corrigan, D.K., 2017. . Analyst 142, 1946-1952.

Li, Q., Zhao, C., Zheng, Z., Weng, S., Chen, Q., Liu, Q., Lin, X., 2017. . Journal of Electroanalytical Chemistry 788, $23-28$.

Li, X., Lee, J.S., Kraatz, H.-B., 2006. . Analytical Chemistry 78, 6096-6101.

Lin, J.-J., Hsu, P.-Y., 2011. . Sensors 11, 8769-8781.

Lisdat, F, Schäfer, D, 2008. . Analytical and Bioanalytical Chemistry 391.

Liu, M., Khan, A., Wang, Z., Liu, Y., Yang, G., Deng, Y., He, N., 2019. . Biosensors and Bioelectronics 130, $174-184$.

Liu, R., Yang, J., Lenigk, R., Bonanno, J., Grodzinski, P., 2004. . Analytical Chemistry 76, 1824-1831.

755 Liu, W., Das, J., Mepham, A.H., Nemr, C.R., Sargent, E.H., Kelley, S.O., 2018. . Lab Chip 18, 1928-1935.

Lobert, P.E., Bourgeois, D, Pampin, R, Akheyar, A, Hagelsieb, L.M., Flandre, D, Remacle, J, 2003. Sensors and Actuators B: Chemical 92, 90 - 97.

Manickam, A, Chevalier, A, McDermott, M, Ellington, AD, Hassibi, A, 2010. .

760 IEEE Transactions on Biomedical Circuits and Systems 4, 379-390.

Marland, J.K.., Blair, E.O., Flynn, B.W., Eva, Huang, L., Kunkler, I.H., Smith, S., Staderini, M., Tsiamis, A., Ward, C., Murray, A.F., Cumming, D.R.., 2018. CMOS Circuits for Biological Sensing and Processing, in: Mitra, S. (Ed.), Springer, Cham, pp. 259-286.

765 Matharu, Z., Daggumati, P., Wang, L., Dorofeeva, T.S., Li, Z., Seker, E., 2017. . ACS Applied Materials \& Interfaces 9, 12959-12966.

Mattiasson, B., Hedström, M., 2016. . TrAC Trends in Analytical Chemistry 79, 233 238.

Medina-Sánchez, M., Ibarlucea, B., Pérez, N., Karnaushenko, D.D., Weiz, S.M.,

770 Baraban, L., Cuniberti, G., Schmidt, O.G., 2016. . Nano Letters 16, 4288-4296.

Miranda-Castro, R., Santos-lvarez, N., Lobo-Castan, M., 2018. . Electroanalysis 30, $1229-1240$.

Moore, E, O’Connell, D, Galvin, P, 2006. . Thin Solid Films 515, 2612 - 2617.

Park, JY., Park, SM., 2009. .Sensors, 9(12), 9513-9532

775 Patterson, A.S., Heithoff, D.M., Ferguson, B.S., Soh, T.H., Mahan, M.J., Plaxco, K.W., 2013. . Applied and Environmental Microbiology 79, 2302-2311.

Nanoflex Ltd. [WWW Document].

Nanomedical Diagnostics Ltd. [WWW Document].

Ngo, H.T., Wang, H.-N., Fales, A.M., Vo-Dinh, T., 2015. . Analytical and

780 Bioanalytical Chemistry 408, 1773-1781.

Oberländer, J., Bromm, A., Wendeler, L., Iken, H., Durán, M., Greeff, A., Kirchner, P., Keusgen, M., Schöning, M., 2015. . physica status solidi (a) 212, 1299-1305. Pruna, R., Baraket, A., Bonhommé, A., Zine, N., Errachid, A., López, M., 2018. . Electrochimica Acta 283, $1632-1639$. 
Purwidyantri, A., Chen, C.-H., Hwang, B.-J., Luo, J.-D., Chiou, C.-C., Tian, Y.-C., Lin, C.-Y., Cheng, C.-H., Lai, C.-S., 2016. . Biosensors and Bioelectronics 77, 1086 1094.

Rajapaksha, R.D.A.A, Hashim, U., Uda, A.M., Fernando, C.A.N., Silva, D.S., 2017. . Microsystem Technologies 23, 5771-5780.

790 Rho, S., Jahng, D., Lim, J., Choi, J., Chang, J., Lee, S., Kim, K., 2008. . Biosensors and Bioelectronics 23, $852-856$.

Dos Santos, B.M., Azevedo, S, Agusil, J.P., Prieto-Simón, B, Sporer, C, Torrents, E, Juárez, A, Teixeira, V, Samitier, J, 2015. . Bioelectrochemistry 101, 146- 152. Scarfi, S., Smith, S., Tabasnikov, A., Schmueser, I., Blair, E.O., Bunting, A.S., Walton, A.J., Murray, A.F., Terry, J.G., 2016. . International Conference on Microelectronic Test Structures (ICMTS) 184-189.

Schmueser, I, Walton, AJ, Terry, JG, Woodvine, HL, 2013. . Faraday Discussions. Sharma, D., Lee, J., Seo, J., Shin, H., 2017. . Sensors 17.

Sharma, S., Huang, Z., Rogers, M., Boutelle, M., Cass, A.E., 2016. . Analytical and Bioanalytical Chemistry 408, 8427-8435.

Shinwari, M., Zhitomirsky, D., Deen, I., Selvaganapathy, P., Deen, M., Landheer, D., 2010. . Sensors 10.

Š́pová, H., Homola, J., 2013. . Analytica Chimica Acta 773, 9 - 23.

Slinker, J.D., Muren, N.B., Gorodetsky, A.A., Barton, J.K., 2010. . Journal of the American Chemical Society 132, 2769-2774.

Somasundaram, S., Holtan, M.D., Easley, C.J., 2018. . Analytical Chemistry 90, 3584-3591.

Soraya, G.V., Chan, J., Nguyen, T.C., Huynh, D.H., Abeyrathne, C.D., Chana, G., Todaro, M., Skafidas, E., Kwan, P., 2018. . Biosensors and Bioelectronics 111, 174810183.

Stulík, K., Amatore, C., Holub, K., Marecek, V., 2000. . Pure and Applied Chemistry 72, 1483-92.

Sultana, R., Reza, N., Kay, N.J., Schmueser, I., Walton, A.J., Terry, J.G., Mount, A.R., Freeman, N.J., 2014. . Electrochimica Acta 126, 98 - 103.

815 Svítková, J., Ignat, T., Švorc, L., Labuda, J., Barek, J., 2016. . Critical Reviews in Analytical Chemistry 46, 248-256.

Sylvestre, J.-P., Poulin, S., Kabashin, A.V., Sacher, E., Meunier, M., Luong, J.H., 2004. . The Journal of Physical Chemistry B 108, 16864-16869.

Terry, J.G., Schmüser, I., Underwood, I., Corrigan, D.K., Freeman, N.J., Bunting,

820 A.S., Mount, A.R., Walton, A.J., 2013. . IET Nanobiotechnology 7, 125-134(9). Tiwari, I., Singh, M., Pandey, C., Sumana, G., 2015. . RSC Advances 5, 6711567124.

Triroj, N., Jaroenapibal, P., Shi, H., Yeh, J.I., Beresford, R., 2011. . Biosensors and Bioelectronics 26, $2927-2933$.

Törer, H., Aydın, E., Sezgintürk, M., 2018. . Analytica Chimica Acta 1024, 65 - 72. Uludag, Y., Olcer, Z., Sagiroglu, M., 2014. . Biosensors and Bioelectronics 57, 85 90 .

Veigas, B., Fortunato, E., Baptista, P.V., 2015. . Sensors 15, 10380-10398. Virgilio, F., Prasciolu, M., Ugo, P., Tormen, M., 2013. . Microelectronic Engineering $111,320-324$. 
Vogt, S, Su, Q, Gutiérrez-Sánchez, C, chemistry, N.-G., 2016. . Analytical chemistry.

Wang, J., 2006. . Biosensors and Bioelectronics 21, 1887 - 1892.

Wang, J., 2000. . Nucleic Acids Research 28, 3011-3016.

835 Wang, J., 1999. . Analytical Chemistry 71, 328-332.

Wang, L., Veselinovic, M., Yang, L., Geiss, B.J., Dandy, D.S., Chen, T., 2017. .

Biosensors and Bioelectronics 87, 646 - 653.

Weng, J., Zhang, J., Li, H., Sun, L., Lin, C., Zhang, Q., 2008. . Analytical Chemistry 80, 7075-7083.

840 Wolfbeis, O.S., 2008. . Analytical Chemistry 80, 4269-4283.

Wu, S., Ye, W., Yang, M., Taghipoor, M., Meissner, R., Brugger, J., Renaud, P., 2015. Sensors and Actuators B: Chemical 216, 105 - 112.

Von Woedtke, T., Jülich, W.-D., Hartmann, V, Stieber, M, Abel, P.., 2002. .

Biosensors and Bioelectronics 17, 373 - 382.

845 Yang, W., Ratinac, K.R., Ringer, S.P., Thordarson, P., Gooding, J.J., Braet, F., 2010. . Angewandte Chemie International Edition 49, 2114-2138.

Yusof, Y., Kazuo, N., 2014. . IEEE Conference on Biomedical Engineering and Sciences, 365-368.

Zimdars, A., Gebala, M., Hartwich, G., Neugebauer, S., Schuhmann, W., 2015. .

850 Talanta $143,19-26$. 